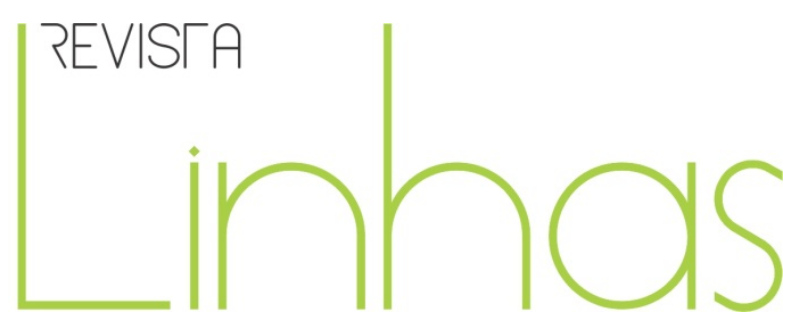

\title{
Resenha do livro Les Inegalites dans l'union europeenne et ailleurs: et si on osait?
}

LANGOUËT, Gabriel. Les Inegalites dans l'union europeenne et ailleurs: et si on osait? Paris: L’Harmattan, 2014, 200 p. (Collection Éducation comparée). ISBN 978-2-343-03037-1.

Vera Lucia Gaspar da Silva

Doutora em Educação pela Faculdade de Educação da Universidade de São Paulo - FEUSP - Brasil vera.gaspar@floripa.com.br

\section{Para citar esta resenha:}

SILVA, Vera Lucia Gaspar da. Resenha do livro Les Inegalites dans I'union europeenne et ailleurs: et si on osait?. Revista Linhas. Florianópolis, v. 15, n. 29, p. 349-352, jul./dez. 2014.

\section{DOI: $10.5965 / 1984723815292014349$}

http://dx.doi.org/10.5965/1984723815292014349

Este livro integra a Coleção "Education Comparée", digirida por Dominique Groux e publicada pela Editora francesa L'Harmattan. Conforme indicado na apresentação, o trabalho se articula à obra anterior do autor, intitulada "Les inégalités entre États et populations de la planète: Trop, c'est trop! (Paris: L'Harmattan, 2011), a qual traz Prefácio de Roger Establet. Esta informação ajuda a situar obra e autor, inscritos na 
sociologia francesa, particularmente aquela ocupada de reflexões e análises que colocam em relevo as desigualdades sociais e seus diferentes modos de produção.

Gabriel Langouët, professor aposentado da Universidade René Descartes (Paris V) e pesquisador do Centro Nacional de Pesquisa Científica - CNRS, conta com uma produção que tem circulação internacional. Entre seus trabalhos destacamos aqui “Technologie de l'éducation et démocratisation de l'enseignement, Méthodes pédagogiques et classes sociales" que conta com prefácio de Viviane Isambert Jamati (Paris: PUF, 1982), "Suffit-il d'innover" (Paris: PUF, 1985), "La démocratisation de l'enseignement aujourd'hui” (Paris: ESF, 1994), "50 ans d'école. Et demain? (Paris: Fabert, 2008), “Les inégalités entre États et populations de la planète. Trop, c'est trop! (Paris: L'Harmattan, 2011). No Brasil destacamos o texto “A escola francesa se democratiza, mas a inserção social torna-se cada vez mais difícil”, publicado em número especial da Revista Perspectiva1 que traz como tema central "Leituras sociológicas em educação", e conta com organização de Nadir Zago e Maria das Dores Daros.

No livro “Les Inégalites dans L'union Européenne et Ailleurs: Et si on osait?, Gabriel Langouët refina as análises sobre as desigualdades sociais apoiado em base empírica que envolve um conjunto respeitável de dados e produz reflexões que entrecruzam aspectos de maneiras variadas, de modo a apresentar um cenário complexo que favorece o aprofundamento da compreensão sociológica. Os dados têm como origem, particularmente, estatísticas produzidas pelo PNUD, basicamente as publicadas no relatório de 2013, correspondente à coleta de 2011. Ao longo de seis capítulos, tais dados são organizados e apresentados em quadros demonstrativos e tabelas (são mais de 30 com diferentes formatos) que sustentam as análises e representam indicadores reveladores de políticas levadas a efeito na e pela União Europeia. Tais indicadores são mobilizados a partir de "três grandes domínios" que interagem no complexo quadro de construção do desenvolvimento humano: o nível material de vida, os indicadores de saúde e os níveis de educação dos jovens e adultos.

\footnotetext{
${ }^{1}$ Periódico publicado pelo Centro de Ciências da Educação da Universidade Federal de Santa Catarina CED/UFSC.

${ }^{2}$ Disponível em https://periodicos.ufsc.br/index.php/perspectiva/issue/view/600/showToc. (Acesso em 06 de julho de 2014).
} 
Para dar forma ao livro, o autor toma como um dos eixos a "pretensa" igualdade que a União Europeia acenou em seu projeto, e as desigualdades que manteve ou foi construindo ao longo do tempo, seja como resultado de políticas externas, seja por efeitos internos tanto dentro da União quanto dos países-membros. Nascida nos anos cinquenta do século passado, como alternativa à contensão de guerras entre nações, a UE foi formalizada nos anos seguintes com progressiva adesão dos Estados e acabou assumindo um contorno econômico que não conseguiu conter a exclusão, ou, nas palavras do autor: "les inégalités qui subsistent entre les États et celles qui perdurent à l'intérieur des États"3 (Langouët: 2014: p. 25).

Na opção sociológica adotada, a obra tem, como adverte seu autor, um duplo objetivo: de um lado colocar a disposição um conhecimento indispensável, ainda que insuficiente, sobre as principais desigualdades que caracterizam os Estados e as populações da União Europeia ao longo de sua "construção"; e de outro lado (mas ao mesmo tempo), mostrar que o melhor caminho seria o da redução das desigualdades a fim de favorecer o desenvolvimento humano do conjunto da população (cf. p. 28).

A estratégia metodológica que dá forma ao estudo comparado apresenta "distâncias e vizinhanças" ${ }^{4}$ entre os indicadores dos países membros da União Europeia correlacionando desdobramentos locais decorrentes da adesão ou não a políticas aprovadas e adotadas pela "União", como exemplo destacamos o uso da moeda única (o Euro). Ainda na composição do quadro comparativo o autor lança mão de um grupo de Estados não integrantes da União Europeia; trata-se de Coreia do Sul, Brasil e Índia cujos indicadores sociais dos últimos anos apresentam "fortes concordâncias" e são mobilizados como uma espécie de contraponto na elaboração das análises.

A crítica às desigualdades produzidas por este "modelo" de organização política dos Estados é contundente, mas supera o caráter denunciatório, mesclando aspectos que vão sendo produzidos e que são produtores das desigualdades explicitadas.

\footnotetext{
3 “... as desigualdades que subsistem entre os Estados e aquelas que perduram no interior dos estados". Tradução livre.

${ }^{4}$ Refiro-me aqui a perspectiva proposta por Denice Catani no texto "Distâncias, Vizinhanças, Relações: Comentários sobre os estudos sócio-histórico-comparados em educação” (In.: NÓVOA, António; SCHRIEWER, Jürgen (Eds.). A difusão mundial da escola. Lisboa: Educa, 2000: p. 143-150).
} 
Desigualdades que, se referidas ao tema que inspira esta coletânea, nos levam a perceber que as políticas educacionais dos diferentes países permanecem priorizando a educação de "herdeiros" em prejuízo, evidentemente, das expectativas e necessidades da maioria dos povos, para quem somente o acesso aos saberes - e não nos referimos apenas aos saberes legítimos - permite se situar no mundo, compreendê-lo e participar de sua transformação.

Recebido em: 30/11/2013 Aprovado em: 21/02/2014

Universidade do Estado de Santa Catarina - UDESC Programa de Pós-Graduação em Educação - PPGE Revista Linhas

Volume 15 - Número 29 - Ano 2014 revistalinhas@gmail.com 